\title{
Determinants of delegation and consultation by managers
}

\author{
GARY YUKL* AND PING PING FU \\ Management Department, School of Business, State University of New York at Albany, \\ Albany, NY 12222, U.S.A.
}

\begin{abstract}
Summary Few studies have identified determinants of delegation and consultation. To investigate this question further, we surveyed managers and subordinates in two samples and interviewed managers individually or in focus groups. The use of delegation and consultation with individual subordinates was determined in part by characteristics of the subordinates and the manager-subordinate relationship. More delegation was used for a subordinate who was competent, shared the leader's task objectives, had worked longer for the manager, was a supervisor also, and had a favorable exchange relationship with the manager. Consultation with a subordinate was predicted by goal congruence, subordinate job level, and quality of the leader-member exchange relationship. The managers acknowledged that developing subordinates and empowering them to do their work were important reasons for delegation, but many managers were reluctant to give up control over important decisions or assign an important task to an inexperienced subordinate. Copyright (C) 1999 John Wiley \& Sons, Ltd.
\end{abstract}

\section{Introduction}

Delegation is a complex, multi-faceted process that includes assigning important new tasks to subordinates, giving subordinates responsibility for decisions formerly handled by the manager, and increasing the amount of latitude and discretion allowed subordinates in how they do their work, including the authority to take action without getting prior approval. Delegation is widely acknowledged to be an essential element of effective management (Yuk1, 1994), and it offers a number of potential benefits, both to the manager and the subordinate. When used in appropriate ways, delegation may improve the speed and quality of decisions, reduce overload for the manager, enrich the subordinate's job, increase the subordinate's intrinsic motivation, and provide opportunities for subordinate development of leadership skills. Delegation is clearly relevant to many topics of current interest in the literature on management of organizations, such as employee involvement, empowerment, decentralization, and self-managed groups.

* Correspondence to: Gary Yukl, Department of Management, School of Business, SUNY at Albany, Albany, NY12222, USA. 
Many practitioner-oriented books and articles have been written about delegation over the past 40 years (e.g. Engel, 1983; Steinmetz, 1976), but only a few empirical studies have been conducted to discover the determinants, facilitating conditions, and outcomes of delegation (see Hackman and Dunphy, 1990). The most comprehensive study on determinants of delegation was conducted by Leana (1986, 1987), but she only studied one type of manager (insurance claims supervisor) in one organization. There is clearly a need for more research on this subject.

Delegation can be contrasted with consultation, which involves getting ideas and concerns from subordinates before making a decision that affects them. Consultation may involve a single subordinate or multiple subordinates. With delegation the authority to make a decision is turned over to a subordinate, whereas with consultation the authority is retained by the manager. How much influence subordinates actually have is the primary distinction among different definitions of consultation. Some theorists (e.g. Heller and Yuk1, 1969; Vroom and Yetton, 1973; Vroom and Jago, 1988) define consultation very narrowly to include only decisions for which the manager has much more influence than a subordinate; these theorists use a different construct such as joint decision-making to describe decisions for which the manager and subordinate have more equal influence. Because this conceptual distinction is difficult to apply when describing actual managerial behavior, we will use the term consultation broadly to include all decisions a subordinate is allowed to influence.

Although less empowering than delegation, consultation is also a form of empowerment because it provides subordinates influence over important decisions. Consultation provides an opportunity for subordinates to voice concerns about adverse consequences of a proposed change. The process of negotiation and joint problem solving that often occurs as part of consultation may reveal possibilities for a mutually acceptable compromise, even when subordinates are not passionate about the manager's goals. During the past half century there has been considerable research on participative leadership, but most of it examined consequences rather than determinants (see Bass, 1990). Relatively few studies have been conducted to identify the conditions that predict how much consultation a manager will use with an individual subordinate.

Two leadership theories appear especially relevant for explaining how managers vary their use of delegation and consultation across subordinates. The Leader-Member Exchange (LMX) theory of leadership describes how the dyadic relationship between a manager and a subordinate develops over time as a result of role-making processes and social exchange between the two parties (Graen and Scandura, 1987; Graen and Uhl-Bien, 1995). Managers typically develop a more favorable exchange relationship with some subordinates than with others. When there is strong mutual trust and loyalty in the exchange relationship, subordinates are provided more responsibility and discretion. A subordinate who is dependable and trustworthy is more likely to be consulted for advice and given additional responsibilities. Several studies have shown that LMX is related to outcomes such as subordinate satisfaction and performance (see Graen and Uhl-Bien, 1995), but there has been little research on the relationship of LMX to leader delegation and consultation.

The Normative Decision Model prescribes conditions under which different decision procedures (such as delegation and consultation) are optimally effective in terms of maximizing decision quality and acceptance (Vroom and Yetton, 1973; Vroom and Jago; 1988). The model was not intended to be descriptive, but prescriptions about the feasibility of using various decision procedures should also help to predict how much a manager will actually use them. Research in which managers were asked how they would make each of several hypothetical decisions indicated that the respondents were influenced by situational variables such as goal congruence and decision importance (see Vroom and Jago, 1988). However, most managers were 
asked to think about decisions involving a group; there has been little research to investigate whether the model applies to dyads.

\section{Research objectives}

The primary purpose of the present study was to investigate likely predictors of delegation and consultation. As in the study by Leana, the focus of our research was on how managers change their behavior for different subordinates, not on how managers differ from each other in their average level of behavior. Some of the predictors were taken from the study by Leana (1986, 1987) to see if her findings could be replicated with different measures and a more heterogeneous sample of managers. We extended her research by including additional predictor variables suggested by the leadership literature. To reduce the problems of confounding and method bias so common in leadership research, we collected data from two sources (managers and subordinates) with two methods (questionnaires and interviews).

\section{Hypotheses}

Five hypotheses are proposed regarding the predictors of delegation and consultation by a manager with an individual subordinate.

\section{Hypothesis 1: More delegation is used with subordinates perceived to have high job competence}

Delegation is more likely to be successful if a subordinate has the job knowledge required by new responsibilities and will take the initiative to deal with problems without waiting for direction. Thus, it is reasonable to expect that a manager will delegate more to a subordinate who is perceived to be competent. In the only field study on this question (Leana, 1986, 1987), subordinate competence was correlated significantly with two measures of delegation, namely a manager's self-reported use of delegation and an objective measure of subordinate discretion to settle insurance claims. In a laboratory study by Ashour and England (1972), the amount of discretion participants said they would allow hypothetical subordinates in a scenario was correlated significantly with subordinate competence.

The relationship of consultation to subordinate job competence is more complex. According to the Vroom-Yetton theory, a manager should use some form of participation when the decision is important and subordinates have relevant information about the decision problem. Competent subordinates are more likely to have such information. However, consultation usually takes longer than delegation, and a manager who is overloaded with responsibilities may prefer delegation over consultation when a subordinate has high expertise and can be trusted to make a good decision (Heller and Yukl, 1969). In the study by Leana (1987), there was a weak, negative correlation between subordinate competence and joint decision making (a strong form of consultation). In view of the lack of a clear rationale for a positive relationship between consultation and subordinate competence, we did not propose any hypothesis about it. 


\section{Hypothesis 2: More delegation and consultation are used with subordinates who share the manager's task objectives}

According to Vroom and Yetton (1973) it is not feasible to use delegation unless a manager and subordinate have the same task objectives. Decision quality and subordinate performance will suffer if control over important decisions is given to a subordinate whose objectives are inconsistent with those of the manager. In a study by Vroom and Jago (1974), managers who were asked how they would make a set of hypothetical decisions said they would not delegate important decisions to a subordinate who did not share their goals. However, goal congruence was not correlated significantly with delegation in the study by Leana (1986), which may have been due to the use of a weak measure of goal congruence. She measured amount of agreement between manager and subordinate on priorities, which is probably less relevant and more difficult to measure than the manager's perception of goal congruence.

According to the Vroom-Yetton model, consultation is more feasible when goal congruence is high, because a subordinate who shares the manager's task objectives is more likely to cooperate in providing the ideas and information needed to make a good decision. Some research asking managers how they would make various types of decisions for a group of subordinates provides support for this proposition (see Vroom and Jago, 1974), but it has not been verified for dyads.

\section{Hypothesis 3: Less delegation is used with subordinates who have worked for the manager only a short time}

There are two reasons for less delegation to a new subordinate. First, a subordinate who is new to the job is likely to have lower job competence and less self-efficacy than one with considerable experience on the job. Second, most managers are reluctant to delegate much responsibility to a subordinate until the person's competence and goal congruence can be assessed. Even if a new subordinate has prior experience in doing the job, the manager will want to determine whether the subordinate is dependable. Over time, more delegation is likely to be used with subordinates who are competent and dependable. The relationship is complicated by the fact that subordinates who have demonstrated exceptional competence are likely to be promoted, whereas incompetent employees are likely to quit or be dismissed. In a static correlational study, there should be a weak, positive correlation between time together and delegation. We did not find any prior studies that directly examined this research question. Leana (1986) found a significant but weak correlation between subordinate job tenure and delegation $(r=0.19)$. However, job tenure (time in job) is not equivalent to time together, because a new manager may be assigned to manage subordinates who have years of experience in their current jobs.

The relationship between time together and consultation is less clear. Time together provides more opportunity to discover whether a subordinate is competent and has congruent task goals. However, for subordinates who have demonstrated they are competent and dependable, managers may increase delegation more than consultation (Leana, 1987). Thus, we did not predict any relationship between time together and consultation. 


\section{Hypothesis 4: More delegation and consultation are used with subordinates who are managers themselves}

Subordinate position level is a dyadic predictor whenever a manager has some direct reports who are supervisors (e.g. assistant manager, project team leader, subunit supervisor) and some who are not (e.g. staff professional, secretary, technicians, salespeople). There are two plausible reasons for more delegation to subordinates who are managers themselves. First, it is more acceptable for a manager to delegate administrative responsibilities to a subordinate manager than to a non-managerial employee. The primary reason for having subordinate managers is to help carry out administrative responsibilities that are too much for one person to handle alone. Moreover, delegation of increased responsibilities is an appropriate way to groom and evaluate a subordinate manager as a likely successor. A second reason for more delegation to a subordinate manager is that a person who already has managerial responsibilities is likely to be perceived as more competent and dependable than someone passed over for promotion or too inexperienced to be eligible for promotion. In a survey study by Blankenship and Miles (1968), perceived discretion to make a final decision was greater for high-level managers than for low-level managers, but the study did not directly examine delegation behavior. No prior study has determined whether subordinate position level is related to delegation independently of subordinate competence.

It is also reasonable to expect managers to use more consultation with subordinates who are managers themselves. A subordinate manager is likely to have related administrative responsibilities that require some consultation by both parties to coordinate decisions and solve joint problems. The relationship between subordinate job level and consultation also reflects the obvious correlation between subordinate job level (a dyadic predictor) and manager job level (a group-level predictor). In comparison to lower-level managers, middle managers have a higher proportion of subordinates who are also managers themselves. A middle manager is usually responsible for coordinating more diverse activities than a lower-level manager, and subordinates are likely to have more expertise than the manager about their own specialized work activities (Vroom and Jago, 1988). The less the relative expertise of a manager, the more important it is to consult with subordinates who possess relevant knowledge and information. Two field studies using manager self-reports found evidence that higher-level managers used a higher overall level of consultation than did lower-level managers (Heller and Yukl, 1969; Jago and Vroom, 1977). We did not find any study that examined subordinate job level as the predictor of consultation by a manager with an individual subordinate.

\section{Hypothesis 5: More delegation and consultation are used when there is a strong exchange relationship between the manager and subordinate}

Leader-member exchange theory implies that greater discretion and involvement are allowed subordinates who are loyal and trustworthy, but few studies have examined the relationship of LMX with either delegation or consultation. Scandura, Graen and Novak (1986) found that LMX correlated significantly $(r=0.45)$ with a subordinate's perceived influence over decisions, which is similar to consultation. Schriesheim, Neider, Scandura and Tepper (1992) found a significant but very weak correlation between LMX and delegation in two samples $(r=0.19$ and $0.22)$. Neither study examined the possibility that the relationship could be accounted for entirely 
by other variables (such as goal congruence or subordinate competence) that may be reflected in LMX scores.

\section{Method}

\section{Samples and procedure}

Survey questionnaires were the primary method of data collection for this study, and interviews were used as a supplementary method. Survey data were collected in three waves over a period of nearly a year. The first sample included 28 middle and lower-level managers and 117 of their subordinates in 12 different organizations. Most of the managers were from public sector agencies, small businesses, or financial organizations (i.e. banking, insurance). Questionnaires were distributed to the managers and their direct subordinates by MBA students who worked in these organizations. Completed questionnaires were returned in sealed envelopes to protect respondent confidentiality. The response rate was 91 per cent for managers and 93 per cent for subordinates. The high response rates were probably due to the fact that each individual was personally asked to participate in the study, and follow-up requests were used with anyone who was late in returning the questionnaire. The average tenure of the managers was 5 years in their current position, and 62 per cent of them were males.

The second sample included 59 middle and lower-level managers and 279 of their direct subordinates in two manufacturing companies and a private, health-care organization (hospital, nursing home, and hospice). Questionnaires were distributed through the company mail with a cover letter from top management explaining the purpose of the study and requesting employees to participate in it. The response rate for the initial survey was 78 per cent for managers and 57 per cent for subordinates. The average tenure of the managers in their current position was 6.3 years, and 47 per cent were males. In a follow-up survey a few months later, 54 of the 59 managers ( 92 per cent) in the second sample provided completed questionnaires. To make the sample more representative, we also administered the follow-up questionnaire at management training workshops to 52 middle managers from several organizations.

\section{Subordinate questionnaire}

Subordinates of the 87 focal managers in the study filled out questionnaires that were confidential but not anonymous (a subordinate's initials were written on the questionnaire to allow matching of data within dyads). If a manager had more than 10 subordinates, we randomly selected 10 of them to be in the study. The subordinate questionnaire had separate sections on demographic variables, job attitudes, and perceptions of the manager's behavior. Subordinate job level was recoded into two levels $(1=$ non-supervisory; $2=$ managerial $)$. Gender was coded as a dummy variable $(1=$ male, $2=$ female $)$. Responses for time together were skewed toward the high end, and they were recoded into four categories to normalize the distribution ( $1=1$ to 6 months; $2=7$ to 18 months; $3=19$ to 36 months; $4=37$ or more months). Information about some of the demographic variables (subordinate gender, age, and education) was collected only for the second sample.

Subordinate LMX was measured by three items adapted from the LMX-7 (Scandura and Graen, 1984). To avoid confounding different constructs, we selected only items that clearly 
describe the quality of the relationship rather than the leader's actual or expected behavior toward the subordinate. The items had seven response choices with verbal anchors for each choice ( $1=$ Strongly disagree; $7=$ Strongly agree). Alpha coefficients for our LMX scale were high in both samples $(0.85,0.84)$, indicating that reliability was not reduced much by shortening the scale.

The behavior scales used for the first sample were adapted from the Managerial Practices Survey (Kim and Yukl, 1996; Yukl, Wall and Lepsinger, 1990). All of the behavior items had five response choices with verbal anchors for each choice $(1=$ Never or not at all; $5=$ Almost always or to a very great extent). Additional items were added to some scales for the second sample to provide a wider variety of examples and improve reliability. Internal consistency reliability for this sample was adequate for all of the behavior scales (the alpha coefficients were 0.80 for delegation, 0.90 for consultation, 0.89 for clarifying, and 0.79 for monitoring). A factor analysis of the subordinate questionnaire yielded separate orthogonal factors for delegation, consultation, clarifying, monitoring, and LMX. The five factors accounted for 65 per cent of the total item variance. The scales and factor loadings for each item can be obtained from the first author.

\section{Manager questionnaire}

The first part of the manager questionnaire measured a variety of demographic and background variables, including type of position, span of control, time in position, age, gender, and highest level of education. In the second part of the questionnaire we used a variation of Leana's ordered ranking procedure to measure a manager's perception of subordinate competence and goal congruence. A manager was asked to write the initials of each participating subordinate above the scale number on a line anchored at both ends by descriptors. The line had eight scale points indicated by numbers. The result was a distribution showing the absolute and relative rating for each subordinate on each dimension (see Appendix 1).

\section{Interviews and follow-up survey}

After the completed questionnaires were returned, individual interviews were conducted with each of the 28 focal managers in the first sample. The interviews were conducted by nine MBA students as part of a group research project. The interview was semi-structured and included a series of open-ended questions with follow-up probes. Most interviews were conducted at the job site during working hours, and the duration of the interview was usually 30 to 40 minutes. The purpose of the interview was to gather information about what was delegated, the criteria used to determine what to delegate to whom, the problems encountered in delegation, and the conditions for successful delegation.

In the second sample, instead of interviewing individual managers we met with managers in small focus groups 3 months after the survey. First we asked the managers to answer a short follow-up questionnaire based on the results from the interviews in sample 1. The questionnaire asked whether a manager delegated different things to different subordinates (no, yes), whether there were any things the manager would not delegate (no, yes), and if so what they were. The managers also rated (on a 4-point scale) the importance of various criteria for determining what to delegate and to whom it should be delegated. The responses provided insights about group-level predictors of delegation as well as dyadic predictors. We used the responses as the basis for questions in the focus groups to stimulate discussion about reasons for delegating, 
problems encountered in delegating, and contextual variables affecting the use of delegation and consultation.

\section{Results}

A preliminary analysis indicated no significant difference in means between the two samples for any variables used in the hypotheses, and the pattern of correlations among variables was also similar for the two samples. The samples were combined to obtain a sufficient sample size for the regression analyses.

\section{Results for analysis of primary survey data}

Table 1 shows the means and standard deviations of variables used in the analysis and the zeroorder correlations among variables. A conservative level of significance was used because of the large sample size and number of correlations. Delegation correlated significantly with subordinate competence and goal congruence (both measured independently from delegation), as well as with job level, time together, and LMX. Consultation was correlated significantly with subordinate competence, goal congruence, time together, job level, and LMX. The only predictor variable that correlated significantly with clarifying and monitoring was LMX. None of the behaviors were correlated significantly with subordinate age, education, or gender.

Hierarchical multiple regression analyses were conducted next to assess the independent and joint effects of the predictor variables. The analyses were made separately for delegation and consultation, and they only included predictors that were significant in the analysis of zero-order correlations. LMX was entered last in order to assess the other relationships in the absence of any distortions caused by inflated criterion correlations for LMX, which were likely because data on LMX and manager behavior were both from the same source. The results for both stages of the analysis are shown in Table 2.

In the first stage of the regression analysis for delegation, competence, goal congruence, job level, and time together were all significant predictors of delegation, consistent with hypotheses 1-4. Our confidence in these findings is increased by the fact that data on goal congruence and subordinate competence came from a different source than data on delegation. Moreover, even though data on subordinate job level and time together came from the same source as the data on delegation, it is unlikely that rater bias had much effect on responses about these objective background variables. LMX was added in the second stage of the regression analysis, and the results for this predictor were also significant (consistent with hypothesis 5). Except for goal congruence, the other predictors remained significant. In summary, four of the five hypotheses about the predictors of delegation were supported by all of the analyses, and the remaining hypothesis (about goal congruence) received partial support.

In the first stage of the regression analysis for consultation, goal congruence and subordinate job level were significant predictors, consistent with hypotheses 2 and 4 . As expected, competence and time together did not predict consultation. LMX was added in the second stage of the regression analysis, and the results for this predictor were also significant (consistent with hypothesis 5). The other two predictors of consultation remained significant after LMX was added. In summary, all three hypotheses about the predictors of consultation were supported by 
Table 1. Means, standard deviations, and correlations

\begin{tabular}{|c|c|c|c|c|c|c|c|c|c|c|c|c|}
\hline Variable & 1 & 2 & 3 & 4 & 5 & 6 & 7 & 8 & 9 & 10 & 11 & 12 \\
\hline 1. Competence & $055^{*}$ & & & & & & & & & & & \\
\hline $\begin{array}{l}\text { 2. Goal congruence } \\
\text { 3. Time together }\end{array}$ & 0.53 * & 0.00 & & & & & & & & & & \\
\hline 4. Job level & $0.14^{*}$ & $0.14^{*}$ & 0.03 & & & & & & & & & \\
\hline 5. Age & $0.26^{*}$ & 0.09 & 0.06 & $0.17^{*}$ & & & & & & & & \\
\hline 6. Education & 0.06 & 0.10 & -0.05 & $0.23^{*}$ & 0.01 & & & & & & & \\
\hline 7. Gender & 0.05 & 0.06 & 0.06 & $-0.20^{*}$ & -0.01 & -0.12 & & & & & & \\
\hline 8. LMX & $0.18^{*}$ & $0.33 *$ & 0.12 & 0.01 & 0.03 & -0.07 & $0.16^{*}$ & & & & & \\
\hline 9. Delegating & $0.29^{*}$ & $0.29 *$ & $0.19^{*}$ & $0.27^{*}$ & 0.08 & 0.14 & 0.01 & $0.46^{*}$ & & & & \\
\hline 10. Consulting & $0.16^{*}$ & $0.32^{*}$ & 0.06 & $0.13^{*}$ & -0.02 & 0.00 & 0.03 & $0.66^{*}$ & $0.55^{*}$ & & & \\
\hline 11. Clarifying & -0.03 & 0.11 & 0.06 & -0.04 & -0.14 & -0.10 & 0.11 & $0.45^{*}$ & $0.23^{*}$ & $0.50^{*}$ & & \\
\hline 12. Monitoring & 0.00 & 0.12 & 0.05 & -0.02 & -0.02 & 0.05 & -0.04 & $0.32^{*}$ & $0.16^{*}$ & $0.39^{*}$ & $0.52^{*}$ & \\
\hline Mean & 6.2 & 6.4 & 2.9 & 1.3 & 39.7 & 2.4 & 1.6 & 5.5 & 3.4 & 3.5 & 3.6 & 1.1 \\
\hline S.D. & 1.4 & 1.5 & 1.0 & 0.6 & 9.8 & 1.1 & 0.5 & 1.3 & 0.8 & 1.0 & 1.0 & 1.0 \\
\hline$N$ of dyads & 390 & 389 & 386 & 393 & 275 & 278 & 278 & 395 & 396 & 396 & 396 & 396 \\
\hline
\end{tabular}

$p<0.01$ for two-tail test of $r$. 
Table 2. Hierarchical multiple regression analysis for key predictors of dyadic delegation and consultation

\begin{tabular}{lcccc}
\hline Predictor variable & Deta & $T$ & Beta & $T$ \\
\hline Step 1 & & & & \\
Competence & 0.12 & $2.21^{*}$ & 0.05 & -0.93 \\
Goal congruence & 0.19 & $3.33 \dagger$ & 0.33 & $5.56 \dagger$ \\
Time together & 0.16 & $3.35 \dagger$ & 0.07 & 1.43 \\
Subord. job level & 0.24 & $5.06 \dagger$ & 0.11 & $2.19^{*}$ \\
Overall $F(\mathrm{df}=4,374)$ & & $21.82 \dagger$ & & $12.17 \dagger$ \\
Adjusted $R^{2}$ & & 0.18 & & 0.11 \\
Step 2 & & & \\
Competence & & $2.58 \dagger$ & -0.03 & -0.55 \\
Goal congruence & 0.14 & 0.95 & 0.10 & $2.10^{*}$ \\
Time together & 0.05 & $2.49 \dagger$ & -0.01 & -0.35 \\
Subord. job level & 0.11 & $5.69 \dagger$ & 0.12 & $3.02 \dagger$ \\
LMX & 0.25 & $8.41 \dagger$ & 0.62 & $14.95 \dagger$ \\
Overall $F(\mathrm{df}=5,372)$ & 0.39 & $34.83 \dagger$ & & $60.05 \dagger$ \\
Adjusted $R^{2}$ & & 0.31 & & 0.44 \\
\hline
\end{tabular}

${ }^{*} p<0.05 ; \dagger p<0.01$.

the results from the regression analysis as well as by the zero-order correlations. We did not conduct a multiple regression analysis for clarifying and monitoring, because no a-priori hypotheses were made for these behaviors, and the only significant predictor of either behavior in the zero-order correlations was LMX.

\section{Results from interviews and the follow-up survey}

Examination of the responses by managers to questions in the interviews and supplementary questionnaire revealed some other interesting findings. Most managers said they delegated different responsibilities to different subordinates (100 per cent in sample 1; 98 per cent in sample 2). Most managers also said there are some responsibilities they do not delegate to anyone (100 per cent in sample 1; 90 per cent in sample 2). Common examples included important, sensitive decisions such as budgeting, financial control, and appraisal of subordinates.

In sample 1, the most frequent answers to the question about reasons for delegating were to develop subordinates, to empower subordinates to do their work better, and to manage time and make better use of subordinates. Similar results were found for the follow-up questionnaire used with sample 2. Table 3 shows how managers rated the importance of different criteria for determining what to delegate. The most important reasons for delegating were to develop subordinates, motivate their commitment, and empower them to do their jobs better (i.e. improve decisions by moving them close to the action; enable subordinates to deal with problems quickly). An important reason for not delegating was that the task or decision involves confidential information. A moderately important reason for delegating was to reduce the manager's workload and manage time better. A moderately important reason for not delegating was that the task or decision was important and central to the manager's role.

The next set of questions in the follow-up questionnaire asked managers to indicate the importance of various factors for determining who should be given a delegated task or decision. The results, shown in Table 4, were generally consistent with the results described earlier for the 
Table 3. Importance of different reasons for delegating or not delegating

\begin{tabular}{lcc}
\hline Reason & Item mean & Mod. or very important \\
\hline Develop subordinate skills and confidence & 3.5 & $97 \%$ \\
Enable subordinates to deal with problems quickly & 3.4 & $91 \%$ \\
Improve decisions by moving them close to the action & 3.4 & $89 \%$ \\
Increase subordinate commitment to a task & 3.5 & $89 \%$ \\
Keep decisions involving confidential information & 3.5 & $87 \%$ \\
Make the job more interesting for subordinates & 3.1 & $78 \%$ \\
Keep tasks and decisions that are very important & 3.0 & $76 \%$ \\
Keep tasks and decisions central to your role & 2.9 & $73 \%$ \\
Reduce your workload to manage time better & 2.9 & $68 \%$ \\
Keep tasks for which mistakes are highly visible & 2.6 & $58 \%$ \\
Keep tasks you can do better than subordinates & 2.6 & $51 \%$ \\
Keep tasks that are difficult to explain to subordinates & 2.4 & $43 \%$ \\
Keep tasks that are difficult to monitor & 2.3 & $39 \%$ \\
Satisfy superiors who want you to delegate more & 1.9 & $24 \%$ \\
Keep tasks that are interesting and enjoyable & 1.9 & $24 \%$ \\
Get rid of tedious tasks you don't want to do & 1.9 & $23 \%$ \\
\hline
\end{tabular}

Data are from 106 managers; the response choices were: 1, not important; 2, slightly important; 3, moderately important; 4 , very important.

Table 4. Reasons for delegation to a particular individual

\begin{tabular}{lcc}
\hline Reason for selecting person & Item mean & Mod. or very important \\
\hline The person is dependable and self reliant & 3.6 & $95 \%$ \\
The person has more expertise than others & 3.4 & $88 \%$ \\
It is related to the person's other responsibilities & 3.2 & $85 \%$ \\
The person needs to develop skills & 3.1 & $76 \%$ \\
The person has the time to do it & 3.0 & $73 \%$ \\
The person really wants to do it & 2.9 & $70 \%$ \\
The person shares your task objectives & 2.9 & $66 \%$ \\
The person deserves it as a reward & 2.6 & $56 \%$ \\
\hline
\end{tabular}

Data are from 106 managers; the response choices were: 1, not relevant; 2, slightly important; 3, moderately important; 4 , very important.

dyadic multiple regression analyses. The most important criteria for selecting a delegation target were subordinate competence and dependability. Goal congruence and the developmental needs of the particular subordinate were rated moderately important. Managers rated subordinate's developmental needs as significantly less important for selecting a delegation target than the subordinate's expertise $(t=-2.8 ; p<0.01, \mathrm{df}=104)$ or dependability $(t=-4.9 ; p<0.01$, $\mathrm{df}=104)$. Thus, even though managers rated subordinate development the most important reason for delegating, they were more inclined to give an important assignment to someone who already had the necessary expertise than to someone who needed to develop it.

\section{Discussion}

Because there has been so little research on the determinants of delegation, a major objective of our study was to see if Leana's results for an homogeneous sample of supervisors in one company 
could be replicated in an hetereogeneous sample of managers from a variety of different organizations. Using a different measure of delegation, we were able to replicate most of Leana's key findings. Like Leana, we found that managers delegated more responsibility to competent subordinates. We found that managers used less delegation with subordinates who had worked for them only a short time, and Leana found that supervisors used less delegation with subordinates who had been on the job only a short time. We found that managers were reluctant to delegate some important and sensitive decisions, which is consistent with Leana's finding that delegation was negatively correlated with decision importance. Finally, we found that a heavy workload was a moderately important reason to use delegation, which is consistent with Leana's finding that supervisors with a heavy workload used more delegation.

In some other respects our results differed from those of Leana. She failed to find a significant relationship between goal congruence and delegation; we found a significant zero-order correlation, and goal congruence was a significant predictor of delegation in the multiple regression analysis before LMX was entered. She found that delegation and consultation were related to subordinate gender and age, but we did not. The few discrepancies in results between the two studies are probably due to differences in the samples and measures. Our stronger results for goal congruence were probably due to the use of a better measure of it.

Our study also included some predictor variables not used by Leana. We found that managers used more delegation and consultation with subordinates who were also managers themselves. This relationship had not been confirmed previously for dyads. We also found that managers used more delegation and consultation with a subordinate when there was a favorable exchange relationship. Our study is the first to find a strong relationship between LMX and delegation.

Delegation and consultation may be regarded as alternative ways to empower subordinates. Delegation allows a subordinate more discretion than consultation, but consultation is suitable for involving subordinates in important decisions that would not normally be delegated to them. Effective managers probably use both behaviors and select the one most suitable at the time for a particular subordinate and task. The moderately high correlation we found between delegation and consultation suggests that managers who believe in empowerment use both forms of behavior more often. The results for LMX suggest that managers use more delegation and consultation with a subordinate when there is a relationship of strong mutual trust. However, the results of the multiple regression analyses showed that LMX is not the only factor managers consider when determining the appropriate amount and form of empowerment.

Another important consideration was subordinate competence, which did not correlate very highly with LMX. The finding that subordinate competence was related to delegation but not to consultation probably reflects the fact that a manager gives up more control with delegation than with consultation. It is less risky to consult with an unexperienced subordinate (weak suggestions do not need to be used) than to give the subordinate primary responsibility for making an important decision.

Time together was another relatively independent predictor of a manager's choice of decision styles. The finding that time together was a determinant of delegation but not consultation probably reflects a reluctance to hand over control of an important task to a subordinate until there is ample opportunity to assess his or her competence and dependability.

Our study provides new insights about the determinants of dyadic delegation and consultation. However, it is important to recognize a major limitation of the research, which is that causality cannot be determined from static correlational analyses of questionnaire data. Some of the relationships we examined probably involve reciprocal causality over time rather than unidirectional causality. Longitudinal, experimental studies with repeated measurement on key variables are needed to verify causality and identify complex, dynamic effects. 


\section{References}

Ashour, A. S. and England, G. (1972). 'Subordinate's assigned level of discretion as a function of leader's personality and situational variables', Journal of Applied Psychology, 56, 120-123.

Bass, B. M. (1990). Handbook of Leadership: A Survey of Theory and Research, Free Press, New York.

Blankenship, L. V. and Miles, R. E. (1968). 'Organizational structure and managerial decision making', Administrative Science Quarterly, 13, 106-120.

Engel, H. M. (1983). How to Delegate: A Guide to Getting Things Done, Gulf Publishing, Houston, TX.

Graen, G. B. and Scandura, T. A. (1987). 'Toward a psychology of dyadic organizing', Research in Organizational Behavior, 9, 175-208.

Graen, G. and Uhl-Bien, M. (1995). 'Relationship-based approach to leadership: Development of leadermember exchange (LMX) theory of leadership over 25 years: Applying a multi-level multi-domain perspective', Leadership Quarterly, 6, 219-247.

Hackman, B. K. and Dunphy, D. C. (1990). 'Managerial delegation'. In: Cooper, C. L. and Robertson, I. T. (Eds) International Review of Industrial and Organizational Psychology, Vol.5, pp. 35-57, Wiley, New York.

Heller, F. and Yukl, G. (1969). 'Participation, managerial decision making, and situational variables', Organizational Behavior and Human Performance, 4, 227-241.

Jago, A. G. and Vroom, V. H. (1977). 'Hierarchical level and leadership style', Organizational Behavior and Human Performance, 18, 131-145.

Kim, H. and Yukl, G. (1996). 'Relationships of managerial effectiveness and advancement to self-reported and subordinate-reported leadership behaviors from the multiple-linkage model', Leadership Quarterly, 6, 361-377.

Leana, C. R. (1986). 'Predictors and consequences of delegation', Academy of Management Journal, 29, 754-774.

Leana, C. R. (1987). 'Power relinquishment versus power sharing: Theoretical clarification and empirical comparison of delegation and participation', Journal of Applied Psychology, 72, 228-233.

Scandura, T. A. and Graen, G. B. (1984). 'Moderating effects of initial leader-member exchange status on the effects of a leadership intervention', Journal of Applied Psychology, 69, 428-436.

Scandura, T. A., Graen, G. B. and Novak, M. A. (1986). 'When managers decide not to decide autocratically: An investigation of leader-member exchange and decision influence', Journal of Applied Psychology, 71, 579-584.

Schriesheim, C. A., Neider, L. L., Scandura, T. A. and Tepper, B. J. (1992). 'Development and preliminary validation of a new scale (LMX-6) to measure leader-member exchange in organizations', Educational and Psychological Measurement, 52, 135-147.

Steinmetz, L. (1976). The Art and Skill of Delegation, Addison-Wesley, Reading, MA.

Vroom, V. H. and Jago, A. G. (1974). 'Decision making as a social process: Normative and descriptive models of leader behavior', Decision Sciences, 5, 743-769.

Vroom, V. H. and Jago, A. G. (1988). The New Leadership: Managing Participation in Organizations, Prentice Hall, Englewood Cliffs, NJ.

Vroom, V. H. and Yetton, P. W. (1973). Leadership and Decision Making, University of Pittsburgh Press, Pittsburgh, PA.

Yukl, G. (1994). Leadership in Organizations, Prentice Hall, Englewood Cliffs, NJ.

Yukl, G., Wall, S. and Lepsinger, R. (1990). 'Preliminary report on validation of the managerial practices survey'. In: Clark, K. E. and Clark, M. B. (Eds) Measures of Leadership, Leadership Library of America, West Orange, NJ, pp. 223-238. 


\section{Appendix 1: Ordered Ranking Task}

On the following scales, please write the initials for each of your direct subordinates above the scale number that indicates where the person falls on that scale. More than one subordinate can be given the same rating, but please try to make some distinctions among subordinates (do not rate all subordinates the same). Also, please try to think about each dimension (scale) separately. Your answers will remain completely confidential. A sample is shown below.

\section{SAMPLE:}

\begin{tabular}{|c|c|c|c|c|c|c|c|c|c|}
\hline & & & & FS & & & & & \\
\hline Weak job & & TT & LR & $\begin{array}{l}\text { KJ } \\
\text { JW }\end{array}$ & $\begin{array}{l}\text { SM } \\
\text { SE }\end{array}$ & GF & $\mathrm{HP}$ & & Strong job \\
\hline knowledge & 1 & 2 & 3 & 4 & 5 & 6 & 7 & 8 & knowledge \\
\hline
\end{tabular}

Job knowledge: The extent to which a subordinate has prior experience, training, and skill that make him or her more capable of doing the work.

$\begin{array}{lllllllllll}\begin{array}{l}\text { Weak job } \\ \text { knowledge }\end{array} & 1 & 2 & 3 & 4 & 5 & 6 & 7 & 8 & \begin{array}{l}\text { Strong job } \\ \text { knowledge }\end{array}\end{array}$

Shared task objectives: How much a subordinate is committed to the same task objectives as you and will make a concerted effort to attain these objectives even when not supervised.

\begin{tabular}{llllllllll}
$\begin{array}{l}\text { Disagrees with your } \\
\text { task objectives }\end{array}$ & 1 & 2 & 3 & 4 & 5 & 6 & 7 & 8 & $\begin{array}{l}\text { Supports your } \\
\text { task objectives }\end{array}$ \\
\hline
\end{tabular}

